CDD: 658.403

\title{
DESENVOLVIMENTO SUSTENTÁVEL EMPRESARIAL: O USO DA GESTÃo DA INFORMAÇÃO
}

SUSTAINABLE BUSINESS DEVELOPMENT: USE OF INFORMATION MANAGEMENT

\author{
Wánderson Cassio Oliveira Araújo \\ Danielly Oliveira Inomata ${ }^{2}$ \\ Gregório Jean Varvakis Rados ${ }^{3}$
}

\begin{abstract}
RESUMO: A sustentabilidade é um tema que está cada vez mais presente na agenda das mais diversas áreas do conhecimento. Em paralelo, temos a consolidação da sustentabilidade na sociedade alicerçada na informação e no conhecimento. Inserido neste contexto, é necessário que as MPEs incorporem a ideia de sustentabilidade em seus processos tendo em vista a sua importância para a economia mundial além dos impactos ambientais que a elas estão relacionados. A exequibilidade é um processo que visa atender as demandas internas e externas da organização, o processo de gestão da informação pode ser um apoio para otimizar a eficiência e a eficácia da organização, considerando o uso de informações que estão disponíveis e que podem tornar-se estratégicas para a organização transformando-as em conhecimento para a geração de soluções inovadoras que atendam às exigências impostas pelo desenvolvimento sustentável. Sugere-se a gestão da informação como um auxiliar no processo para a eficácia do triple bottom line nas MPEs. A partir de uma revisão teórica da área de gestão da informação como auxiliar nesse processo, sugerindo a adoção de práticas dentro do fluxo de informação que ajudará a empresa a realizar o manejo sustentável de seus processos, desde o uso da informação para gerar conhecimento inovador para a resolução de questões relacionadas com a sustentabilidade e também agregar valor sobre as questões sociais, econômicas e ambientais da empresa.
\end{abstract}

PAlavraS-Chave: Gestão da informação. Fluxo de informação. Desenvolvimento sustentável empresarial. Micro e pequenas empresas. Exequibilidade.

ABSTRACT: Sustainability is a topic that is increasingly present on the agenda of the most diverse areas of knowledge. In parallel we have the consolidation of the sustainability in society based on information and knowledge. Inserted in this context it is necessary that MSEs incorporate the idea of sustainability into its processes in view of its importance for the world economy, and the environmental impacts related to it. The feasibility is a process designed to meet internal and external demands of the organization, then the information management process can be a support to optimize efficiency and effectiveness of the organization considering the use of information that is available and that can become strategic for organization transforming them into knowledge for the creation of innovative solutions that meet the demands imposed by sustainable development. It is suggested the information management as an assist in the process for the effectiveness of the triple bottom line in MSEs. From a theoretical review of the area of information management as assisting in this process suggesting the introduction of practices within the flow of information that will help the company to carry out the sustainable management of its processes, from the use of information to generate innovative knowledge for the resolution of issues related with sustainability and also add value to the company on social, economic and environmental issues.

KEYWORDS: Information management. Flow of information. Corporate sustainable development. Micro and small enterprises. Feasibility.

\footnotetext{
1 Mestre em Ciência da Informação, pela Universidade Federal de Santa Catarina (UFSC). Professor do Departamento de Ciência da Informação da Universidade Federal de Rondônia. E-mail: wcassio@unir.com

${ }^{2}$ Mestre e doutoranda em Ciência da Informação, UFSC. Bolsista modalidade A da Fundação de Amparo à Pesquisa do Estado do Amazonas. E-mail: inomata.danielly@gmail.com

${ }^{3}$ Professor do Programa de Pós-Graduação em Engenharia e Gestão do Conhecimento e do Departamento de Ciência da Informação, da UFSC. E-mail: g.varvakis@ufsc.br
}

Submetido em: 28/06/2013 - Aceito em: 22/08/2014

\begin{tabular}{l} 
(C) Rev. digit. bibliotecon. cienc. inf. \\
\hline
\end{tabular}




\section{INTRODUÇÃ̃o}

A sociedade humana passa frequentemente por mudanças em suas diversas estruturas sociais, econômicas, políticas, educacionais e tecnológicas. Nos modelos de gestão não é diferente. A formulação de um modelo que responda as demandas de um novo contexto, ao identificar gaps, trazendo novas abordagens de método, escopo e objetivos além de novos conceitos tecnológicos, econômicos, sociais e ambientais que estejam em sintonia com as necessidades de seu tempo, foi um processo contínuo em distintos períodos históricos.

Como uma pluralidade de rótulos, seja Sociedade da Informação (MATTELART, 2002) ou Sociedade do Conhecimento (NAISBITT; ABURDENE, 2000), é consenso, independentemente do termo utilizado, que as necessidades dos seres humanos, grupos sociais, empresas, países e do mundo como um todo são convergentes no que tange às questões sociais, econômicas e, nos últimos anos, ambientais.

Um exemplo da configuração deste cenário são as conferências de Estocolmo (1972), Rio de Janeiro (1992), Quioto (1997), Haia (2000), Bonn (2001), Copenhagen (2009), Cancun (2010), e mais recente, em 2012, no Rio de Janeiro conhecida como Rio+20 que demonstram o reflexo do desejo de um mundo mais sustentável (INPE, 2012).

O fato do desenvolvimento sustentável está em pauta nos mais variados campos do conhecimento, talvez seja o motivo pelo qual o próprio conceito ainda esteja se estruturando. Embora alguns esforços tenham ocorrido - como o empenhado no Relatório Our Future Common $^{4}$ (UNITED NATIONS, 2012) ou aqueles empenhados no conceito triple bottom line ${ }^{5}$ criado por John Elkington (LEE et al., 2012) -, o conceito de desenvolvimento sustentável precisa de uma definição globalmente uniforme, pois essa ideia está em construção passando constantemente por processos de revisão, ampliação e aperfeiçoamento (SOUBBOTINA, 2004).

Concomitante a isso, considerando que a sustentabilidade é um processo que está integrado nos mais variados âmbitos, entende-se que a exequibilidade da sua gestão necessita do uso de informações de alto nível, ao passo que a geração de conhecimento será crucial para o desenvolvimento de soluções inovadoras para os problemas que envolvem os processos ligados à sustentabilidade. É nesta vertente que o presente trabalho se desenvolve, o qual objetiva aproximar os fluxos de informação como suporte a sustentabilidade organizacional,

\footnotetext{
${ }^{4}$ Também conhecido como Relatório Brundtland, produzido pela Comissão Mundial sobre o Meio Ambiente e Desenvolvimento da Organização das Nações Unidas.

${ }^{5}$ Conceito que abrange o equilíbrio das questões sociais, econômicas e ambientais dentro do conceito do desenvolvimento sustentável.
}

\begin{tabular}{l|l|l|l|l|l|l}
\hline (C) Rev. digit. bibliotecon. cienc. inf. & Campinas, SP & v.12 & n.3 & p.119-135 & set/dez. 2014 & ISSN 1678-765X \\
\hline
\end{tabular}


ao entregar produtos com valor agregado a seus clientes, no contexto das micro e pequenas empresas (MPEs) e contribuir com o aumento da discussão de dois temas que podem ser aliados no atendimento de requisitos em voga na sociedade.

Quanto aos procedimentos metodológicos, esse é um estudo descritivo e analítico, a partir de um levantamento bibliográfico e uma fundamentação conceitual, na qual se abordam reflexões sobre a gestão da informação e o fluxo de informação como fator de suporte à efetivação da gestão da sustentabilidade empresarial.

\section{CARACTERIZAÇÃo dAS MiCro e PEQUENAS EMPRESAS No bRASIL E A SUSTENTABILIDADE}

No Brasil as empresas são divididas em cinco categorias: empreendedores individuais, micro empresas, pequenas empresas, médias empresas e grandes empresas. Essa divisão está relacionada ao faturamento bruto da empresa no período anual. Os valores para essa classificação estão definidos na lei complementar $n^{\circ}$ 139, de 10 de novembro de 2011, descritas no quadro 1.

QUADRO 1 - Classificação micro e pequena empresa Brasil

\begin{tabular}{cc}
\hline Tipo & Valor Máximo \\
\hline Micro Empresa & $\mathrm{R} 360$ mil \\
Pequena Empresa & $\mathrm{R} \$ 3,6$ milhões \\
\hline
\end{tabular}

Fonte: Lei complementar no 139 (BRASIL, 2011)

As MPEs são responsáveis aproximadamente por 20\% do PIB, 99\% das empresas e $60 \%$ dos empregos do país (SEBRAE, 2012). Com relação a inserção do tema sustentabilidade no ambiente das MPEs, sondagem do Serviço Brasileiro de Apoio à Micro e Pequena Empresa - SEBRAE - revelou alguns dados sobre as ações dos empresários. A pesquisa foi realizada com 3.912 micro e pequenos empresários, em nível nacional e em todas as áreas de atuação (TABELA 1).

TABELA 1 - Sondagem em MPES sobre o tema sustentabilidade - Brasil/2012

\begin{tabular}{lcc}
\hline \multicolumn{1}{c}{ Ação } & Sim & Não \\
\hline Identificam o tema sustentabilidade como uma oportunidade de ganhos. & $46 \%$ & $54 \%$ \\
\hline Possuía algum conhecimento sobre a temática sustentabilidade. & $65 \%$ & $35 \%$ \\
Executam coleta seletiva de lixo. & $70,2 \%$ & $29,8 \%$ \\
\hline Controlam o consumo de papel. & $72,4 \%$ & $27,6 \%$ \\
Controlam o consumo de água. & $80,6 \%$ & $19,4 \%$ \\
Controlam o consumo de energia. & $81,7 \%$ & $18,3 \%$ \\
Destinação adequada de resíduos tóxicos & $65,6 \%$ & $34,4 \%$ \\
\hline
\end{tabular}

\begin{tabular}{l|l|l|l|l|l|l} 
(C) Rev. digit. bibliotecon. cienc. inf. & Campinas, SP & v.12 & n.3 & p.119-135 & set/dez. 2014 & ISSN 1678-765X \\
\hline
\end{tabular}




\begin{tabular}{|c|c|c|}
\hline Uso matérias-primas ou materiais recicláveis no processo produtivo. & $48,3 \%$ & $51,7 \%$ \\
\hline Captação de água da chuva e/ou reutilização de água. & $16,5 \%$ & $83,4 \%$ \\
\hline Reciclagem de pilhas, baterias ou pneus. & $48,1 \%$ & $50,9 \%$ \\
\hline
\end{tabular}

Fonte: SEBRAE (2012)

Essa sondagem mostra que ações que levam à sustentabilidade, mesmo que de forma pontual e desestruturada, estão cada vez mais em pauta dentro das MPEs. Esse processo de adaptação das empresas para atender a demanda da sustentabilidade acaba por criar uma carga de informações que não passam por um processo adequado de tratamento e consequentemente resultam em processos falhos e que não agregam valor a cultura organizacional da empresa interferindo diretamente nos objetivos que a empresa deseja alcançar, a sustentabilidade.

\section{GESTÃo da INFORMAÇÃo E A EXEQUiblidAdE DA GESTÃo do DESENVOLVIMENTO SUSTENTÁVEL EMPRESARIAL.}

Os modelos de gestão sofrem modificações para atender as demandas da sociedade. No começo do século passado a era da produção em massa (1920-1950) e a era da eficiência (1950-1970) eram reflexo dos chamando modelos tradicionais de gestão. A partir de era da qualidade (1970-1990) e da era da competitividade (1990-2000) configurou-se os chamados: modelos de gestão que são caracterizados pela Administração japonesa; Administração participativa; Administração empreendedora; Administração holística.

Salienta-se, também, que os modelos emergentes de gestão que abrangem a empresa virtual, a gestão do conhecimento e os modelos quânticos e biológicos, a teoria do caos e da complexidade estão tomando forma e criando novas formas de gerir as empresas (SANTOS, 2001).

Chiavenato (2011) corrobora a ideia dos modelos emergentes de gestão, como resultado da era da informação que se iniciou nos anos 1990 e que transformou a forma de atuação das empresas com as tecnologias de informação e comunicação (TIC), tendo papel de destaque nessa transformação, cujo diferencial nesse novo paradigma são: o conhecimento; a digitalização; a virtualização; a molecularização; integração/redes integradas; desintermediação; convergência; produz-consumo; imediatismo; a globalização; e a discordância.

A sustentabilidade está inserida nas novas abordagens de gestão e dentro dos aspectos que irão moldar o futuro da gestão empresarial (CHIAVENATO, 2011), mostrando-se como um desafio, uma vez que, o equilíbrio proposto pela ideia do triple bottom line ainda é urn 
processo que precisa se tornar exequível dentro das empresas, e ao que tange às MPEs esse desafio ainda é mais presente, uma vez que, as mesmas, em sua grande maioria, possuem limitações de capital financeiro e de capital intelectual.

Neste trabalho utiliza-se a visão de efetivação do desenvolvimento sustentável proposta por Pacheco Júnior et al. (2011, p. 78), a qual defende que a:

[...] dimensão da exequibilidade diz respeito à capacidade e habilidade de uma organização em atender às demandas explícitas e implícitas das sociedades, mostrando serem os seus resultados convergentes ao conceito de desenvolvimento sustentável. Trata-se de ações produzidas pela organização que resultem e/ou possam resultar em benefícios sistêmicos, o que requer antecipação em relação aos riscos de possíveis impactos de seus produtos e processos às sociedades nas quais tem influência direta e/ou indireta. Tais benefícios, evidente, uma vez que se trata de sustentabilidade, são das esferas ambiental, social e econômica, e com as quais uma organização deve se situar perante as sociedades para atender aos seus requisitos, temporais e espaciais.

Assim usaremos da ideia de exequibilidade fazendo um paralelo com o conceito de gestão da informação, imbricados na visão de McGee e Prusak (1994), Marchiori (2002) e Valentim e Texeira (2012), como o processo que engloba as ações e estratégias para a obtenção e utilização de recursos humanos, tecnológicos, financeiros, físicos e suas correlações que são utilizados para o processo de gerir as informações internas e externas em formatos diversos e para posteriormente ser oferecida como um insumo de grande utilidade e com valor agregado para pessoas, grupos e organizações objetivando atender suas necessidades informacionais.

A gestão da informação poderá servir como suporte para as ações que irão direcionar a resolução das demandas explicitas e implícitas, as quais estão ligadas a MPE. O acesso às informações de alto nível dará suporte para a tomada de decisões, o monitoramento do ambiente no qual a empresa está inserida, as ações dos concorrentes, a facilidade no acesso a indicadores ambientais, sociais e econômicos, a construção de um processo de guarda da produção informacional da empresa para posterior recuperação entre outros benefícios. Por fim, a gestão da informação servirá como uma aliada à construção dos produtos informacionais ${ }^{6}$.

\footnotetext{
${ }^{6}$ Juran conceitua que produtos são bens e serviços, o primeiro como algo físico e, o segundo, como trabalho feito para outro. Neste trabalho, mantem-se a essência do conceito de produto, acrescentando que ocorre uma somatória de bens e serviços que agregam valor, sendo o produto do tipo informacional. 


\section{FLUXO DE INFORMAÇÃo COMO SUPORTE À GESTÃo DA SUSTENTABILIDADE}

A informação está presente em todas as atividades de uma organização, e nas mais variadas formas e formatos. Porém, por mais que vivamos em uma sociedade ávida pelo consumo e produção de informação não nos diferenciamos de sociedades anteriores à nossa. Todas as sociedades se utilizavam, em algum grau, da informação (CASTELLS, 2005), no entanto, o que nos diferencia é o uso das TIC que modificaram drasticamente a forma de consumir e produzir informação tendo os canais de armazenamento e disseminação como o ápice do processo de quebra de barreiras territoriais para o acesso de informações.

Tal qual todos os consumidores de informação, as MPEs também precisam adquirir informações relevantes para suas demandas informacionais. Essas informações podem ser adquiridas das mais variadas formas levando em consideração sua relevância, qualidade e custo/benefício. Para Choo (2006, p. 27) a informação é um componente intrínseco que está envolto em todos os processos que permeiam a empresa

[...] sem uma clara compreensão dos processos organizacionais e humanos pelos quais a informação se transforma em percepção, conhecimento e ação, as empresas não são capazes de perceber a importância de suas fontes e tecnologias de informação.

As informações adquiridas necessitam passar por um tratamento que resultem na criação de valor para quem a utiliza. As TIC, erroneamente, são consideradas a solução dos problemas informacionais nas empresas, mas o que é necessário é uma visão que coloque as pessoas em primeiro plano na administração dessa informação para geração de conhecimento e resultando em tomadas de decisões, resoluções de problemas, inovação, otimização de produtos e processos e etc. (DAVENPORT; PRUSAK, 1998).

Nas MPEs não é diferente, quando se trata da gestão da sustentabilidade, o uso correto das informações como fator à exequibilidade faz-se necessário a visão de que as informações que os colaboradores da empresa possuem devem ser compartilhadas com os demais colaboradores para a geração de conhecimento e, consequentemente, atingir a sustentabilidade no contexto organizacional.

Nesse sentindo temos o processo responsável pela validação das informações que irão ser utilizadas pela empresa, o fluxo de informação. Para Altíssimo (2009) o fluxo de informação é o processo responsável pela transmissão de informações de um emissor para um receptor e responde pelo compartilhamento de informações por um determinado espaço de tempo. Vital, Floriani e Varvakis (2010, p.85-86) defendem que 
Os fluxos de informação permitem o estabelecimento das etapas de obtenção, tratamento, armazenamento, distribuição, disseminação e uso da informação no contexto organizacional. Uma das funções essenciais dos fluxos informacionais é dotar os gestores de subsídios imprescindíveis ao processo de tomada de decisões.

$\mathrm{Na}$ perspectiva desses autores o fluxo de informação está altamente relacionado à ação, ou seja, orientado à tomada de decisão.

Para Le Coadic (2004), a inexistência e ineficácia de um fluxo de informações organizado, estruturado e relevante irá comprometer as funções de todos os níveis da organização resultando em processos falhos e impossíveis de alcançar sucesso e resolver suas demandas.

O fluxo de informação é composto por etapas que interligadas propiciam a criação de valor, armazenamento e uso eficaz e eficiente das informações em toda a empresa. A figura 1 descreve as etapas que devem ser respeitadas dentro do processo do fluxo informacional. A escolha do modelo se deu por ser baseado em outros modelos presentes na literatura, por ser o mais recente e por ser o único que possui a etapa de descarte.

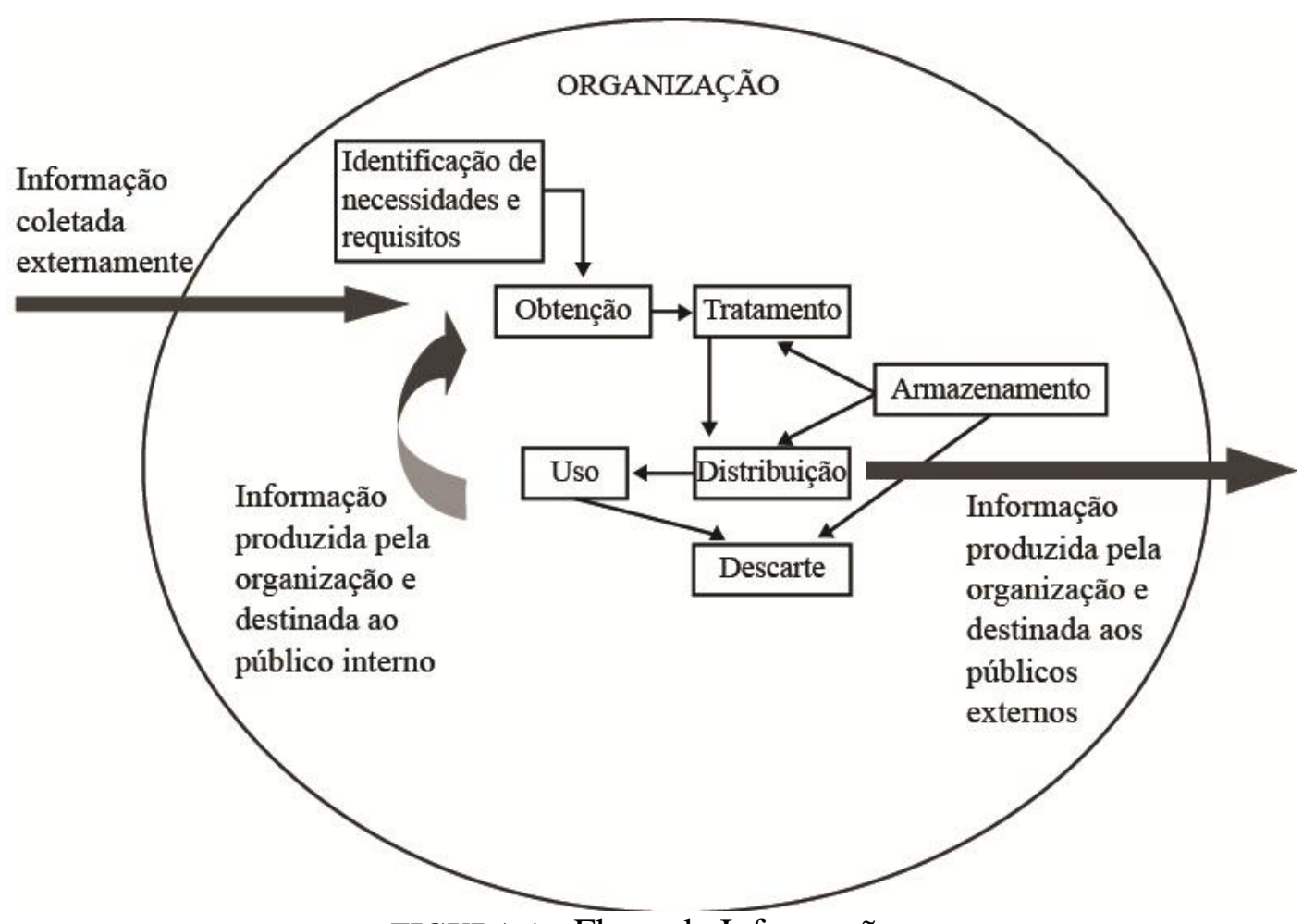

FIGURA 1 - Fluxo de Informação.

Fonte: Beal (2009).

Vital, Floriani e Varvakis (2010), afirmam que os modelos presentes na literatura não possuem diferenças extremas em suas etapas. Para os autores, à medida que um novo modelo é instituído ele acaba por agregar etapas já presentes nos modelos anteriores. 
O fluxo de informação (FIGURA 1) se inicia a partir da identificação de necessidades e requisitos que é o processo que orienta o planejamento informacional levando em consideração o público que se quer atingir. Agindo como a ação que aciona o fluxo de informação e estabelece o processo contínuo que é seguido pela obtenção de informações através das fontes de informação, pelo tratamento da informação tornando à acessível e de fácil localização, o armazenamento da informação que será responsável por assegurar e conservar as informações adquiridas para posterior recuperação, a distribuição da informação que é responsável por levar a informação a quem precisa, o uso que pode ser considerada a parte mais importante do fluxo de informação, pois é através da combinação de informações que é possível a criação de novos conhecimentos e por fim o descarte que inutiliza as informações que não possuem mais utilidade levando em consideração normas legais, políticas operacionais e exigências internais da empresa (BEAL, 2009).

E neste processo, a combinação de novas informações convertidas em insumos para a criação do conhecimento é um fluxo que impulsiona a identificação de novas necessidades de informação, por considerar-se o fluxo dinâmico e contínuo.

\section{IMPLICAÇões PARA A PRÁtICA}

A própria empresa é uma verdadeira fonte de informação, pois produz informações dos mais variados tipos intermitentemente (CAMPELO, 2000), sendo assim, a geração de produtos informacionais é uma extensão da empresa.

Essa premissa nos traz o viés da gestão da informação, quando se pensa na empresa como uma fonte de informação logo se pensa que as informações estratégicas para o negócio sejam gerenciadas para disseminação e uso como fontes de informação e/ou insumo para o processo de exequibilidade da gestão do desenvolvimento sustentável.

No quadro 02, são sugeridas ações para o comportamento do fluxo de informação dentro da perspectiva da sustentabilidade.

QUADRO 2 - Etapas, ações e implicações do fluxo de informação

ETAPA AÇÕES IMPLICAÇÕES


Definir claramente os processos são fatores importantes para o input. A necessidade pode ser de caráter interno (mudança da cultura organizacional, redução de desperdícios e etc.) ou externo (solicitação dos stakeholders, legislação ambiental e etc.).

Determinar de que forma o uso da gestão da informação servirá para a promoção e divulgação da exequibilidade a partir da cultura organizacional.

Objetivar a prospecção de informações que irão suportar o processo do triple bottom line.

Definir as fontes de informação a serem utilizadas é necessário para que a empresa tenha um direcionamento informacional visando otimizar a aquisição de informações relevantes. Além do monitoramento ambiental que é responsável pela aquisição de informações relativas ao mercado, aos concorrentes, às mudanças tecnológicas, às tendências políticas e socioeconômicas e etc.

Descentralizar o tratamento das informações,
possibilitando que setores distintos o façam.
Pode ter limitações ao que tange sua qualidade
se considerarmos a falta de um profissional
adequado para a função, haja vista as limitações
financeiras e de pessoal da MPE.
Utilizar meios digitais para o armazenamento de
informações o que irá gerar economia de papel e
espaço além de agilizar o processo de
recuperação e compartilhamento dessas
informações.
Definir a utilização do processo de gestão
eletrônica de documentos, conhecido como
GED, e o uso de armazenamento de dados em
nuvens são soluções que podem ser inseridas na
realidade econômica das MPEs.
Compartilhar informações de forma
direcionadas por meio de disseminação seletiva
de informações - DSI - e por sistemas de
recuperação de informação, assim os envolvidos
no processo de exequibilidade terão uma gama
de possibilidade de aquisição de informações
tanto as que lhe são direcionadas como as que
ele busca.
E.

O pensamento a longo prazo, nesse processo, pode servir como motor para as ações que servirão como suporte para a efetividade do fluxo de informação visando a gestão da sustentabilidade.

Uma cultura organizacional alinhada tanto no chão de fábrica como nos cargos de gerência será fator crucial para que a demanda informacional seja identificada.

A falta de capital financeiro para aquisição de informações de alto nível nas MPEs pode ser um entrave no processo de obtenção de informações, mas que pode ser contornado por intermédio do uso de fontes de fontes de baixo custo e as informações em acesso aberto.

Informações que não são estruturadas podem influenciar na efetividade do processo de gestão da sustentabilidade na empresa, pois a informação não estruturada pode abranger e representar um grande ativo informacional que é desprezado, em parte, pelas informações estruturadas.

Uma solução possível seria a criação de um vocabulário controlado que abrangesse as necessidades da informacionais da empresa, além do treinamento dos colaboradores para que as informações a serem tratadas possuam uma consistência e padronização de formatos, normalização e vocabulário visando uma organização homogênea da informação tratadas.

O armazenamento criará um estoque informacional que dará suporte para os processos que visem a exequibilidade da gestão da sustentabilidade na MPE estando sempre à disposição dos colabores para que a geração de conhecimento visando a resolução de demandas seja contínua e esteja embasado nas informações para suporte e nos conhecimentos da network da empresa.

Nesse processo a empresa pode incentivar as suas diversas áreas a possuírem um gatekeeper tendo em mente que a divisão de tarefas para a disseminação de informações para toda a empresa irá resultar em informações específicas das áreas que a divulga e para os colaboradores em geral além de não sobrecarregar um único colaborador ou setor da empresa. Se o colaborador está alinhando com a ideia da gestão da sustentabilidade essa disseminação da informação será feita de forma direcionada a alcançar a exequibilidade na empresa. 
Eliminar barreiras organizacionais através do compartilhamento de informações que serão úteis para o conjunto de colaboradores.

Entender que as informações devem ser usadas de forma a criar uma consciência coletiva para a

○ criação de conhecimento evitando o aparecimento de feudos informacionais.

Utilizar a informação para processos de inovação incremental, resolução de entraves nos problemas além de dar suporte nas ações de benchmark visando a ações da gestão da sustentabilidade na MPE.

Seguir as normas formais criadas pela empresa visando a proteção de informações sigilosas e de documentos importantes além de estar alinhado com o monitoramento ambiental em que a empresa está inserida, uma vez que, a mudança de legislações, regulamentações, normas técnicas e etc. Utilizar mapas de temporalidade são essenciais.
O compartilhamento e uso de informações pode não ser a solução pra o processo de exequibilidade, mas fica claro que dará suporte para tomadas de decisão e criação de conhecimentos que além de agregar valor às ações da empresa irão resultar na solução dos problemas que irão aparecer ao decorrer do processo de implementação da gestão da sustentabilidade.

Resultam na mudança de processos da empresa fazendo assim com que a atualização e descarte ou inutilização da informação antiga seja um processo necessário.

O armazenamento das informações em formato digital evitaria o descarte, e não reciclagem, de grande quantidade de papel.

Fonte: Desenvolvido pelos autores

O conjunto de ações e implicações são oriundas de diversos autores (BEAL, 2009; BEUREN, 2009; CUNHA, 2001; CHIAVENATO, 2000; DAVENPORT; PRUSAK, 1998; GOMES E BRAGA, 2007; GRÁCIO; FADEL, 2010; FREIRE et al., 2012; OECD, 2005; SILVA, 2005; SMITH; FADEL, 2011; SOLTERO, 2003) para representar a ideia de que processos bem definidos são fundamentais para os fluxos de informação, desde o input até o uso da informação. Vale ressaltar que o comportamento informacional dos usuários é um fato crucial para que essas informações sejam usadas de forma eficiente e eficaz.

\section{PRODUTOS INFORMACIONAIS}

Como resultado do fluxo de informação se obtém os produtos informacionais que servirão como suporte para que o desenvolvimento sustentável empresarial seja executável. Os produtos informacionais devem ser direcionados a suprir todas as áreas do triple bottom line tendo como objetivo ações que possibilitem a criação de conhecimento que irá dar suporte para as demandas informacionais internas e externas da empresa.

Para Choo (2006, p 76), os produtos informacionais fornecem as estruturas para que a empresa possa "se manter informada e construir a sua base de conhecimento". Para o autor os produtos informacionais tem a função de suportar diferentes horizontes temporais e de abranger diferentes focos de ação da informação. Conforme sustentado por McGee e Prusak 
(1994), os produtos informacionais são o resultado final do processamento da informação interna e externa afim de sistematiza-la para que ela seja usada a fim de suprir as necessidades dos indivíduos, grupo ou da organização. Fadel et al. (2010, p. 26), afirmam que "conhecer as necessidades dos usuários é fundamental para que possamos planejar, construir, gerir e avaliar serviços e produtos informacionais", com relação a isso posiciona-se da seguinte forma: identificar as necessidades dos clientes é fundamental para a composição e entrega de produtos informacionais.

A gestão da informação deve resultar em um artefato que possibilite, a todos os níveis da empresa, a utilização da informação, de forma clara e concisa, tendo em vista o atendimento das necessidades inerentes à sustentabilidade empresarial. Sob esta perspectiva, 0 uso da informação é a parte principal do processo da gestão da informação (BEAL, 2007). No entanto, entende-se que quanto maior a qualidade dos produtos informacionais, maior é a eficiência e eficácia do uso da informação.

Nesse contexto são propostos três blocos que agregam produtos informacionais referentes a um diferente aspecto do triple bottom line, justificando:

i) No aspecto econômico busca-se elencar produtos informacionais que possam subsidiar a tomada de decisão de caráter financeiro com objetivo a possibilitar melhor uso dos recursos da organização tendo em vista a criação de relatórios técnico-financeiros visando a redução de desperdícios de tempo e retrabalho; ii) No aspecto social os produtos informacionais possibilitam que a organização conheça sua influência interna, diante seus colaborares, e externa, diante a sociedade, de modo a desenvolver estratégias para melhoria do bem estar das pessoas em sua infinidade de aspectos; iii) No aspecto ambiental, os produtos informacionais possuem o papel de formalizar o estado da arte das questões ambientais da empresa, assim, possibilitando a tomada de decisões para fins ambientais, bem como, a formatação de ações que visem contribuir para tal questão na organização.

Para exemplificar são sugeridos possíveis produtos informacionais, apresentados nos quadros 3, 4 e 5 divididos, respectivamente, nos aspectos econômico, social e ambiental:

QUADRO 3 - Produtos informacionais aspecto econômico. PRODUTOS INFORMACIONAIS ASPECTO ECONÔMICO

\begin{tabular}{cll}
\hline PRODUTO & \multicolumn{1}{c}{ DESCRIÇÃO } & OBJETIVO \\
Indicadores & Conjunto de informações referente & Melhor utilização dos recursos da empresa visando \\
Econômicos da & aos resultados econômicos da & a economia e uso consciente dos recursos. \\
Empresa. & empresa. & \\
Indicadores de & Conjunto de informações referente & Melhor gestão dos recursos resultando em \\
\hline
\end{tabular}

\begin{tabular}{l|l|l|l|l|l|l}
\hline (C) Rev. digit. bibliotecon. cienc. inf. & Campinas, SP & v.12 & n.3 & p.119-135 & set/dez. 2014 & ISSN 1678-765X \\
\hline
\end{tabular}


Custo e aos custos de produção da empresa. diminuição de desperdícios na produção.

Produtividade.

Indicadores

Financeiros de

Pessoal

Conjunto de informações referente Monitor dos resultados econômicos tendo em vista às questões econômicas que os proprietários, colaboradores, clientes, envolvem as pessoas ligadas à fornecedores e a sociedade objetivando empresa: salários, benefícios e etc. atendimento das necessidades financeiras.

Fonte: Desenvolvido pelos autores

QUADRO 4- Produtos informacionais aspecto social. PRODUTOS INFORMACIONAIS ASPECTO SOCIAL

\begin{tabular}{|c|c|c|}
\hline PRODUTO & DESCRIÇÃO & OBJETIVO \\
\hline $\begin{array}{l}\text { Indicadores } \\
\text { Sociais da } \\
\text { Empresa }\end{array}$ & $\begin{array}{l}\text { Conjunto de informações referente } \\
\text { aos resultados sociais da empresa }\end{array}$ & $\begin{array}{l}\text { Conhecer as reais necessidades que envolvem os } \\
\text { funcionários e a comunidade em que a empresa está } \\
\text { inserida. }\end{array}$ \\
\hline $\begin{array}{l}\text { Transparência } \\
\text { de } \\
\text { Remuneração }\end{array}$ & $\begin{array}{l}\text { Disponibilização de dados } \\
\text { referentes à remuneração e posição } \\
\text { na empresa. }\end{array}$ & $\begin{array}{l}\text { Disseminar informações visando a adequação da } \\
\text { remuneração e das condições de trabalhos dos } \\
\text { colaboradores. }\end{array}$ \\
\hline $\begin{array}{l}\text { Manual de Boas } \\
\text { Práticas Para a } \\
\text { Comunidade }\end{array}$ & \begin{tabular}{lcr} 
Disseminação de & \multicolumn{2}{c}{ informações } \\
estruturadas, & visando & a \\
sustentabilidade, & para & a \\
comunidade onde a empresa está \\
inserida.
\end{tabular} & $\begin{array}{l}\text { Compartilhar o conhecimento dos colaboradores da } \\
\text { empresa com a comunidade. }\end{array}$ \\
\hline
\end{tabular}

Fonte: Desenvolvido pelos autores

QUADRO 5 - Produtos informacionais aspecto ambiental.

PRODUTOS INFORMACIONAIS ASPECTO AMBIENTAL

\begin{tabular}{|c|c|c|}
\hline PRODUTO & DESCRIÇÃO & OBJETIVO \\
\hline $\begin{array}{l}\text { Indicadores } \\
\text { Ambientais da } \\
\text { Empresa }\end{array}$ & $\begin{array}{l}\text { Conjunto de informações } \\
\text { referente aos resultados } \\
\text { ambientais da empresa }\end{array}$ & $\begin{array}{l}\text { Conhecer a realidade dos processos, em nível ambiental, } \\
\text { em que a empresa está inserida visando adoção de } \\
\text { melhores práticas ambientais. }\end{array}$ \\
\hline $\begin{array}{l}\text { Diretrizes de } \\
\text { Consumo } \\
\text { Consciente. }\end{array}$ & $\begin{array}{l}\text { Formatação de diretrizes que } \\
\text { visem a redução de } \\
\text { desperdício. }\end{array}$ & $\begin{array}{l}\text { Redução do consumo de recursos em todos os setores e a } \\
\text { estimulação do uso consciente. Diminuição de gastos com } \\
\text { energia, água, consertos de bens tangíveis e etc. }\end{array}$ \\
\hline $\begin{array}{l}\text { Base de Dados } \\
\text { de Produtos } \\
\text { Tangíveis. }\end{array}$ & $\begin{array}{l}\text { Portfólio de maquinário, } \\
\text { móveis, eletroeletrônicos e } \\
\text { bens tangíveis em geral. }\end{array}$ & $\begin{array}{l}\text { Manter constante atualização do bens tangíveis envolvidos } \\
\text { nos processos de produtos objetivando a adequação da } \\
\text { produção com as práticas sustentáveis que bens inovadores } \\
\text { pode oferecer tais como: produção mais limpa, economia } \\
\text { de energia elétrica, economia de água, tempo de vida } \\
\text { maior do produto e etc. }\end{array}$ \\
\hline
\end{tabular}

Fonte: Desenvolvido pelos autores

Com produtos informacionais bem definidos o compartilhamento de informações são de fácil acesso a todos os envolvidos na empresa. Consequentemente, a geração de conhecimento promove a exequibilidade, a qual está suportada pelos produtos informacionais que servirão como artefatos para que a otimização dos processos, redução de custos de operação sejam alcançados. Além de promover ações como auxiliar nos processos de comunicação internos e externos, mostrar o papel estratégico da informação no ambiente 
empresarial, as atividades que ela influência e o uso de informações de alto nível e de fontes confiáveis (GREEF; FREITAS, 2012).

Vale ressaltar que os produtos sugeridos foram elaborados em observação (i) a ideia de Choo (2003) quando afirma que as tomadas de decisões são baseadas no arranjo de informações de forma a criar um direcionamento para a solução de um problema, criando valor, pois a utilização da informação de forma solta não tem valor agregado; e, (ii) e a ideia de que os produtos informacionais são resultados de processos que certamente ocorrem em organizações, como as MPEs.

\section{CONSIDERAÇõés FINAIS}

A sustentabilidade é um desafio que deve ser incorporado na totalidade dos processos das MPEs. A gestão da informação é uma proposta para a exequibilidade da gestão da sustentabilidade em micro em pequenas empresas uma vez que as limitações financeiras e de pessoal podem criar um problema para adoções de medidas, rumo ao desenvolvimento sustentável empresarial, que necessitem de maior fluxo de capital financeiro e intelectual.

As empresas de pequeno porte possuem vantagens em relação às empresas de maior porte, uma vez que possuem a capacidade de se conectar com oportunidades, tornando-se fornecedores sustentáveis em níveis globais de abastecimento podendo criar suas capacidades de inovação e mudança organizacional resultando em vantagens em cima de seus concorrentes ao que tange à exequibilidade da gestão do desenvolvimento sustentável (MOORE; MANRING, 2008).

Como já alertavam Nonaka e Takeuchi (1997), as empresas vivem em ambientes de incerteza nos seus mais variados campos, tanto a partir da adaptação passiva como a interação ativa, mesmo que algumas partes da organização tenham uma visão passiva e estática é necessário a conscientização que a empresa pode se transformar e para isso a criação de informação e conhecimento no ambiente devem ser eficientes e utilizados de forma dinâmica tendo os atores da empresa uma função ativa nesse processo. Com o alinhamento da cultura organizacional da empresa se voltando para ações que visem a exequibilidade da gestão do desenvolvimento sustentável empresarial a organização pode se utilizar das informações e conhecimentos de forma a alcançar seus objetivos econômicos, mas acima de tudo criar um 
alinhamento com as necessidades globais e traçar objetivos sociais e ambientais a serem alcançados, perfazendo assim a ideia da gestão da sustentabilidade.

Os produtos informacionais como resultado de todo o processo da gestão da informação, podem auxiliar no processo de gestão da sustentabilidade, considerando que o objetivo da gestão da informação é utiliza-la para a efetivação da gestão do desenvolvimento sustentável empresarial, para direcionar o fluxo informacional, para uma vertente que resulte em produtos que darão suporte para essa ação.

Este trabalho reuniu ideias que podem ser testadas na prática. E não exclui a possibilidade de expansão dos construtos e dos produtos informacionais que podem ser gerados pelo fluxo de informação. Sendo assim, recomenda-se para trabalhos futuros (i) a aplicabilidade desses construtos na prática de MPEs; (ii) levantamento do estado-da-arte de produtos informacionais como resultado do fluxo de informação em organizações; (iii) o estudo quantitativo de trabalhos na área com o enfoque da sustentabilidade e gestão da informação.

\section{REFERÊNCIAS}

ALTÍSSIMO, T. L. Cultura organizacional, fluxo de informações e gestão do conhecimento: um estudo de caso. 2009. 168f. Dissertação (Mestrado em Ciência da Informação) - Universidade Federal de Santa Catarina, Florianópolis, 2009.

BEAL, Adriana. Gestão estratégica da informação: como transformar a informação e a tecnologia da informação em fatores de crescimento e de alto desempenho nas organizações. São Paulo: Atlas, 2007.

BEUREN, Ilse Maria. Gerenciamento da Informação: um recurso estratégico no processo de gestão empresarial. São Paulo: Atlas, 2009.

BRASIL. Senado Federal. Lei complementar no 139. Brasília: Subsecretaria de Informações, 2011.

CUNHA, Murilo Bastos da. Para saber mais: fontes de informação em ciência e tecnologia. Brasília: Briquet de Lemos, 2001.

CAMPELO, Bernardete Santos. Organizações como fonte de informação. In: CAMPELO, Bernardete Santos; CEDÓN, Beatriz Valadares; KREMER, Jeannete Marguerite. Fontes de informação para pesquisadores e profissionais. Belo Horizonte: Ed. Ufmg, 2000. p. 35-48.

CASTELLS, M. A sociedade em rede. 8. ed. São Paulo: Paz e Terra, 2005. 
CHIAVENATO, Idalberto. Administração: teoria, processos e práticas. São Paulo: Makron Books, 2000.

CHIAVENATO, Idalberto. Introdução à teoria geral da administração. Rio de Janeiro: Elsevier, 2011.

CHOO, Chun Wei. A organização do conhecimento: como as organizações usam a informação para criar significado, construir conhecimento e tomar decisões. 2. ed. São Paulo: SENAC, 2006.

CHOO, Chun Wei. Gestão de Informação para a organização inteligente: a arte de explorar o meio ambiente. Lisboa: Editorial Caminho, 2003.

DAVENPORT, Thomas H.; PRUSAK, Laurence. Ecologia da Informação. São Paulo: Futura, 1998.

FADEL, Bárbara et al. Gestão, mediação e uso da informação. In: VALENTIM, Marta. Gestão, mediação e uso da informação. São Paulo: Cultura Acadêmica, 2010. p. 13-32.

FREIRE, Patrícia de Sá et al. Memória organizacional e seu papel na gestão do conhecimento. Revista de Ciências da Administração, Florianópolis, v. 14, n. 33, p.41-51, ago. 2012.

GOMES, Elisabeth; BRAGA, Fabiane. Termo de referência para atuação do Sistema SEBRAE em inteligência competitiva. Brasília: Sebrae, 2007.

GRÁCIO, José Carlos Abbud; FADEL, Bárbara. Estratégias de preservação digital. In: VALENTIM, Marta. Gestão, mediação e uso da informação. São Paulo: Cultura Acadêmica, 2010. p. 59-84.

GREEF, Ana Carolina; FREITAS, Maria do Carmo Duarte. Fluxo enxuto de informação: um novo conceito. Perspectivas em Ciência da Informação, Belo Horizonte, v. 17, n. 1, p.3755, jan./mar. 2012.

INPE (Brasil). O futuro que queremos: economia verde, desenvolvimento sustentável e erradicação da pobreza. São José Dos Campos: INPE, 2012.

LE COADIC, I. F. A ciência da Informação. 2. ed. Brasília: Briquet de Lemos, 2004.

LEE, Sora; GEUMA, Youngjung; LEE, Hakyeon; PARK Yongtae. Dynamic and multidimensional measurement of product-service system (PSS) sustainability: a triple bottom line (TBL)-based system dynamics approach. Journal of Cleaner Production, v. 32, p. 173182, set. 2012.

MARCHIORI, M.R. Cultura organizacional: conhecimento estratégico nos relacionamentos e na comunicação com os empregados. São Paulo, 2002. Tese (Doutorado em Ciências Sociais) - Escola de Comunicação e Artes, Universidade de São Paulo.

MATTELART, A. História da sociedade da informação. São Paulo: Loyola, 2002. 
MCGEE, J.; PRUSAK, L. Gerenciamento estratégico da informação. Rio de Janeiro: Campus, 1994.

MOORE, Samuel B.; MANRING, Susan L. Strategy development in small and medium sized enterprises for sustainability and increased value creation. Journal of Cleaner Production, v. 17, n.2, p.276-282, ago. 2009.

NAISBITT, Jhon; ABURDENE, Patrícia. Megatrends 2000: New directions for tomorrow. França: OECD, 2000.

NONAKA, Ikujiro; TAKEUCHI, Hirotaka. Criação de conhecimento na empresa: como as empresas japonesas geram a dinâmica da inovação. Rio de Janeiro: Elsevier, 1997.

OECD (França). Manual de Oslo: diretrizes para coleta e interpretação de dados sobre inovação. Tradução de Flávia Gouveia. 3. ed. Brasília: Finep, 2005.

PACHECO JÚNIOR, Waldemar et al. Sustentabilidade empresarial e a dimensão da exequibilidade. Navus: revista de gestão e tecnologia, Florianópolis, v. 1, n. 1, p.67-81, jul./dez. 2011.

SANTOS, Antônio Raimundo dos et al. Gestão do conhecimento como modelo Empresarial. Brasília: Serpro, 2001.

SEBRAE (Brasil). Análise do emprego: Fevereiro/2012. Brasília: Sebrae, 2012. Disponível em: < http://www.sebrae.com.br/customizado/estudos-e-pesquisas/temas-

estrategicos/emprego/Analise\%20do\%20CAGED\%202012\%2002.pdf >. Acesso em: 28 jun. 2013.

SEBRAE (Brasil). MPE DATA. Brasília: Sebrae, 2012.

SEBRAE (Brasil). O que pensam as micro e pequenas empresas sobre sustentabilidade. Brasília: Sebrae, 2012.

SILVA, Severino Francisco da. Marketing de Serviços: fundamentos, análises e prática no setor de saúde. Maceió: Edufal, 2005.

SMITH, Marinês Santana Justo; FADEL, Bárbara. Gestão da informação e sustentabilidade: uma relação dependente da cultura organizacional. Revista Edicic, Marília, v. 1, n. 3, p.164179, jul./set. 2011.

SOLTERO, Alonso Pérez. Gestão do conhecimento na solução de problemas de gestão da qualidade. In: TERRA, José Claudio Cyrineu; KRUGLIANSKAS, Isak. Gestão do

Conhecimento em pequenas e médias empresas. Rio de Janeiro: Campus, 2003. p. 81-104.

SOUBBOTINA, T. P. Beyond economic growth: An introduction to sustainable development. Washington: World Bank, 2004.

The World Bank, 2004. 


\section{UNITED NATIONS. Report of the World Commission on Environment and}

Development: our common future. NGO Committee on Education: Nova York, 1987.

Disponível em: < http://www.un-documents.net/wced-ocf.htm>. Acesso em: 28 jun. 2013.

VALENTIM, Marta Lígia Pomim; TEIXEIRA, Thiciane Mary Carvalho. Fluxos de informação e linguagem em ambientes organizacionais. Informação e Sociedade, João Pessoa, v. 22, n. 2, p.151-156, maio/ago. 2012.

VITAL, Luciane Paula; FLORIANI, Vivian Mengarda; VARVAKIS, Gregório.

Gerenciamento do fluxo de informação como suporte ao processo de tomada de decisão.

Informação \& Informação, Londrina, v. 15, n. 1, p.85-103, jun/jul 2010. Disponível em: < http://www.uel.br/revistas/uel/index.php/informacao/article/view/5335>. Acesso em: 28 jun. 2013.

\section{Como citar este artigo:}

ARAÚJO, Wánderson Cassio Oliveira; INOMATA, Danielly Oliveira; RADOS, Gregório Jean Varvakis. Desenvlvimento Sustentável Empresarial: O Uso da Gestão da Informação. Rev. digit. bibliotecon. cienc. inf., Campinas, SP, v.12, n.3, p.119-135, set/dez. 2014. ISSN 1678-765X. Disponível em: <http://www.sbu.unicamp.br/seer/ojs/index.php/rbci>. Acesso em: 31 ago. 2014. 